\title{
Investigation the Effect of Country-of-Origin on Consumer Perception and Purchase Intention of Luxury Brands: Case Study - Luxury Branded of Switzer Watches
}

\author{
Mohammad Ali Abdolvand, Atoosa Forough* and Sam Tavakkoli Targhi \\ Department of Business Management, Science and Research Branch, Islamic Azad University, Tehran, Iran
}

\begin{abstract}
The influence of Country-of-Origin $(\mathrm{CoO})$ has been the focus on a lot of studies in international marketing fields The concepts of consumer perception and purchase intention have a mutual relationship; assume importance in the study of country of origin effects. This research attempts to investigate the influence of country of origin towards consumer perception and purchase intention of luxury branded of Switzer watches in context of Iran. Finally regression analysis was used on data in order to test hypothesizes of study. The results strengthens our understanding of the $\mathrm{CoO}$ effect to consumer's purchasing intention specially when product's country of origin considering luxury brands. These results also contribute for a company that wishes to expand internationally in a geographic area and to the theoretical controversy concerning the importance of $\mathrm{CoO}$ in the consumer perception and purchasing intention on decision making process.
\end{abstract}

Keywords: Country-of-Origin (CoO); Consumer perception; Purchase intention; Luxury brands

\section{Introduction}

The effect of Country-of-Origin ( $\mathrm{CoO})$ on consumers' perceptions and purchasing intentions is a common theme in marketing research $[1,2]$. CoO effect refers to how consumers perceive products emanating from a particular country [3]. Country-of-origin images occur at two levels. At a macro level, mention of a particular country may convey a general image, while at a micro, or product class level, a more specific image will be created [4]. Wang and Lamb [5] concluded that the willingness of US customers to buy foreign produced goods was partially determined by the economic, political and cultural environments of the country of origin. Wall and Heslop [6] found that country images were closely related to level of political development. However, that for marketing purposes the most constructive perspective for analysis is the micro or product class level [4].

The importance of $\mathrm{CoO}$ in product evaluation and purchase intention cannot be ignored, especially in luxury branded products. Although the term luxury brand is used very often, it is appropriate to realize that there are different meanings associated with the term. The concept of branding is arguably a powerful marketing strategy used by high quality branded exports and more recently luxury branded products in order to justify low country image perceptions as tradeoffs for high quality raw materials or expert artisan techniques $[7,8]$. However, the study includes additional elements, such as design, price, and guarantee, which can influence the purchasing intention of consumers.

The choice of these variables depends on the definition of what a luxury brand is. Researchers generally agree about the lack of substantial definitions of luxury, that is to say, definitions based on general intrinsic characteristics of products and techniques employed, or on techno-economic characteristics of the industry [9]. The common denominators are beauty, rarity, quality, and price, and also an inspirational brand endorsing the product.

The present study investigates and focuses specifically on the effects of $\mathrm{CoO}$ on the consumer perception as well as purchasing intention of consumers to buy and recommend luxury branded products that are of multi-country affiliations. Regardless of the perspective used, prior research in the field of luxury shows the particular importance that brands play as vectors of strategies that consumers use in their decision-making processes [10-14]. The study focuses on this sector as the internationalization of business is inseparable from its economic development in recent years. In this context, brands conventionally use the argument of $\mathrm{CoO}$ in their international communication strategies. After describing the conceptual framework and methodology for the study, this research presents the findings.

\section{Literature Review}

Previous researchers working on the effects of $\mathrm{CoO}$ consist of two directions. On one direction, they consider the composition of product-country images $[2,3,16]$. On the other direction, they have an interest in how consumers use $\mathrm{CoO}$ as an evaluation of product quality $[1,17,18]$. One of the most comprehensive studies in this area, by Hong and Wyer [19], considered four possible explanations of how country-of-origin information can affect product evaluation. First, it could influence interpretation of other available product attribute information. Second, it could provide a heuristic basis for evaluation without considering other attribute information. Third, it could act as an attribute in itself. Fourth, it could influence the attention paid to other attribute information, thus affecting impact of this information. Their results mostly supported the contention that a product's country of origin stimulates a subject's interest in the product, and leads them to think more extensively about the product information

*Corresponding author: Atoosa Forough, Ph.D. Student, Department of Business Management, Science and Research Branch, Islamic Azad University Tehran, Iran, Tel: +98-4486517982; E-mail: atousa.forough@srbiau.ac.ir

Received September 12, 2017; Accepted September 25, 2017; Published October 03, 2017

Citation: Abdolvand MA, Forough A, Targhi ST (2017) Investigation the Effect of Country-of-Origin on Consumer Perception and Purchase Intention of Luxury Brands: Case Study - Luxury Branded of Switzer Watches. J Account Mark 6: 255. doi: 10.4172/2168-9601.1000255

Copyright: (c) 2017 Abdolvand MA, et al. This is an open-access article distributed under the terms of the Creative Commons Attribution License, which permits unrestricted use, distribution, and reproduction in any medium, provided the original author and source are credited. 
Citation: Abdolvand MA, Forough A, Targhi ST (2017) Investigation the Effect of Country-of-Origin on Consumer Perception and Purchase Intention of Luxury Brands: Case Study - Luxury Branded of Switzer Watches. J Account Mark 6: 255. doi: 10.4172/2168-9601.1000255

Page 2 of 5

and its evaluative implications [20]. This article is part of this second perspective, and examines the influence of $\mathrm{CoO}$ on perceptions and purchasing intentions of consumers in the field of luxury goods. The $\mathrm{CoO}$ impacts consumer perceptions and intentions through the image of the product's $\mathrm{CoO}$. The image is the representation of a specific country, which consumers associate with the products $[21,22]$.

Other work $[15,23,24]$ shows the impact of $\mathrm{CoO}$ on the process of consumer decision making to be relatively low in studies combining several factors. One of the most important criticisms of research concerning $\mathrm{CoO}$ is that the latter has a real impact on product evaluation in the (unrealistic) event of other information not varying. This research therefore includes, in addition to $\mathrm{CoO}$, other variables involved in how consumers assess and choose luxury goods. Luxury branded products are perceived by consumers to be handmade or manufactured by artisans [25,26] using time honored traditions [27], and/or natural ingredients $[28,29]$. Luxury brands with a long standing culmination of history, traditional cultures, regions and beliefs can exude a distinct uniqueness and nostalgic impression that adds to its authenticity [27-30]. As consumers evaluate branded products originating from a particular country with ingredients branded or sourced from another country, they will draw on existing knowledge or pre-existing beliefs of that country which in turn affects their perception that results in the evaluation of the overall "product category" of that particular country. Therefore, a positive level of congruency is usually achieved when a comparable fit is found between the country perceptions of the ingredient authenticity and the country of brand [31].

\section{Methodology}

This article focus on understanding and examine the relative influence of $\mathrm{CoO}$ on the consumer perception and purchasing intention to purchase luxury branded of Switzer watches in context of Iran:

1. Independent variables in this study are manufacturing process and product technological complexity.

2. Moderator variables are Country-of-Origin and consumer perception

3. Dependent variable is purchase intention.

Present study answers these issues using the key research question: Does $\mathrm{CoO}$ influence on consumer perception, purchase intention and consumer's willingness to buy luxury branded products?

This focus informs 5 hypotheses. The first important step is to specify the research context when attempting to identify luxury goods in a purchasing intention.

First hypothesis (H1): $\mathrm{CoO}$ is relatively important for consumer perception of luxury branded goods.
Second hypothesis $(\mathrm{H} 2)$ : $\mathrm{CoO}$ is relatively important for purchase intention of luxury branded goods.

Third hypothesis (H3): Consumer perception is relatively important for purchase intention of luxury branded goods.

Forth hypothesis (H4): Manufacturing process is relatively important for the role of $\mathrm{CoO}$ on consumer perception and purchase intention of luxury branded goods.

Fifth hypothesis (H5): Product technological complexity is relatively important for the role of $\mathrm{CoO}$ on consumer perception and purchase intention of luxury branded goods.

For testing hypotheses of the study, regression analysis was used. Using this method requires some prerequisites that are:

1. There should not be correlation between errors, means errors should be independent.

2. Errors should have normal distribution.

In order to check independence between errors, Durbin-Watson test was used. The DW value should be between 1.5 and 2.5 to reject correlation between errors. For all hypothesis of this study two above conditions were tested and for all of the hypotheses they were satisfied. By the way, for all hypotheses, Durbin-Watson values were between 1.5 and 2.5 and means errors are independent. The model which used in this article was developed to examine the effect of country-of-origin on consumer perception and purchase intention of luxury branded of Switzer watches in context of Iran.

This model examines the relationship between manufacturing process, product technological complexity variables and Country-ofOrigin; and the influence of $\mathrm{CoO}$, consumer perception and purchase intention toward luxury branded product. Figure 1 presents the conceptual model of this research.

The research is applied in terms of the objective, and descriptiveanalytical in terms of data collection. The research population consists of consumer of luxury brands of Switzer watches. To determine the sample size of consumers, due to the unlimited clients, using Cochrane method 150 samples were considered. Luxury brand consumers sample was selected among consumers of watches in a simple random method. This research involves interviewing customers of the research team. The data collection tool was a questionnaire for structured interview consisted of two parts: demographic data, and questions about the relationship between $\mathrm{CoO}$ and consumer perception and purchase intention of them.

The survey instrument was developed using established scales such as consumer's need for consumer perception towards branded products (a 6-item scale by Wood and Darling [32]), consumer

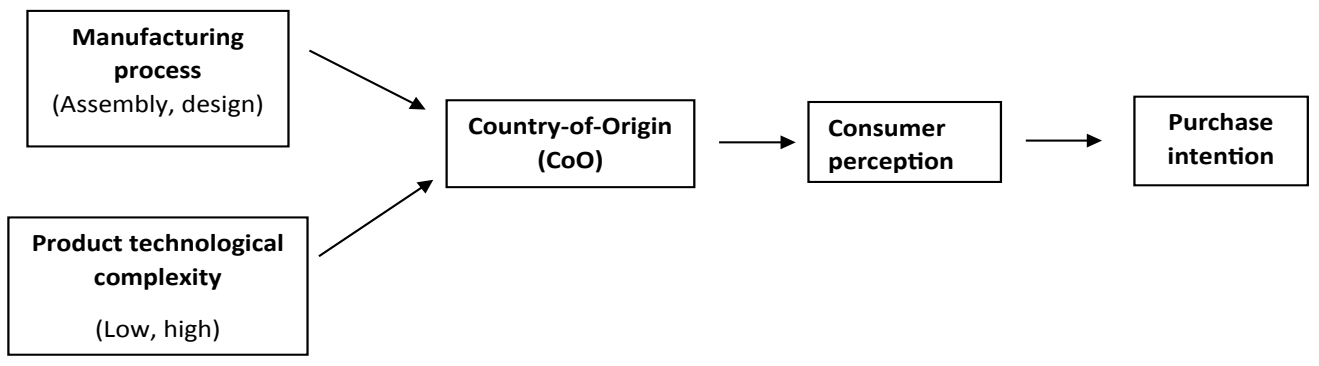

Figure 1: Conceptual model. 
Citation: Abdolvand MA, Forough A, Targhi ST (2017) Investigation the Effect of Country-of-Origin on Consumer Perception and Purchase Intention of Luxury Brands: Case Study - Luxury Branded of Switzer Watches. J Account Mark 6: 255. doi: 10.4172/2168-9601.1000255

Page 3 of 5

intention to purchase (a 6-item scale by Bower and Landreth [33]), manufacturing process and product technological complexity (a 3-item scale by Maxham and Netemeyer [34]) and country-of-origin (a 4-item scale by Park et al. [35]). The questions asked respondents to express their opinions and evaluations on a seven-point Likert scale with 1 representing "strongly disagree" and 7 representing "strongly agree".

Reliability and validity of the test was approved by experts. To determine the reliability of the questionnaire, the Cronbach's alpha was used. In pre-test, using 45 questionnaires and in SPSS software, Cronbach's alpha and validity of the questionnaire was determined. Results suggested that reliability of the questionnaire questions was 81.4 percent, and since the alpha calculated is more than $70 \%$, it can be concluded that the reliability of the questionnaire is largely guaranteed, and the impact of chance is not considerable. In other words, the alpha obtained for the questionnaire indicates a favorable situation. The structure of the sample respects the age and gender distribution of the total population of the country. The sample comprises $65.3 \%$ women and $34.7 \%$ men, and the research team defines the following age categories: aged under 20 years, from 20 to 39 , from 40 to 59, and 60 years and over.

Students from the Shahre Ray branch of Islamic Azad University involved administered the questionnaire; their task was to find respondents in line with the age and gender quotas mentioned above and to help respondents fill in the questionnaire, explaining the questions if needed. The students' role was also to ensure that respondents chose brands belonging to the watches. After collecting the questionnaires, data were classified, and using correlation and linear regression analysis to determine the individual effect of each of the independent variables on the dependent variable, were analyzed using SPSS software.

\section{Results}

The results of demographic data are presented in Table 1 . The sample comprises $65.3 \%$ women and $34.7 \%$ men, and the research team defines the following age categories: $15.3 \%$ respondents were aged less than 20 years, $36 \%$ were aged between 20 to 39 years, 32\% from 40 to 59 , and $16.7 \%$ were aged 60 years and over. Also $61.3 \%$ of respondents were single and $38.7 \%$ of them were married.

\begin{tabular}{|l|c|c|}
\hline Demographic variables & Number & Percentage \\
\hline Sex & 98 & 65.3 \\
\hline Male & 52 & 34.7 \\
\hline Female & 23 & 15.3 \\
\hline Age (in years) & 54 & 36 \\
\hline Lower than 20 & 48 & 32 \\
\hline $20-39$ & 25 & 16.7 \\
\hline $40-59$ & & \\
\hline 60 and above & 6 & 4 \\
\hline Education & 28 & 18.6 \\
\hline Lower than high school diploma & 46 & 30.6 \\
\hline High school diploma & 62 & 41.3 \\
\hline Associate's degree & 8 & 5.5 \\
\hline Bachelor's degree & & \\
\hline Master's degree and higher & 92 & 61.3 \\
\hline Marital status & 58 & 38.7 \\
\hline Single & & \\
\hline Married & & \\
\hline
\end{tabular}

Table 1: Distribution of demographic variables of consumers of luxury branded of Switzer watches.
In order to test the study's hypotheses, a series of regressions were used to analyze the relationships between the predictors (independent variables) and the dependent variables.

The hypotheses and results are as follows:

Hypothesis 1: $\mathrm{CoO}$ is relatively important for consumer perception of luxury branded goods.

Hypothesis 2: $\mathrm{CoO}$ is relatively important for purchase intention of luxury branded goods.

Hypothesis 3: Consumer perception is relatively important for purchase intention of luxury branded goods.

Hypothesis 4: Manufacturing process is relatively important for the role of $\mathrm{CoO}$ on consumer perception and purchase intention of luxury branded goods.

Hypothesis 5: Product technological complexity is relatively important for the role of $\mathrm{CoO}$ on consumer perception and purchase intention of luxury branded goods.

Country-of-origin on consumer perception was significant at the 0.05 level. Thus, H1 are fully supported (Table 2). Country-of-origin and Consumer perception on purchase intention were significant at the 0.05 level. Thus, $\mathrm{H} 2$ and $\mathrm{H} 3$ are fully supported (Tables 3 and 4). Manufacturing process and product technological complexity on $\mathrm{CoO}$ were significant at the 0.05 level. Thus, $\mathrm{H} 4$ and H5 are fully supported (Tables 5 and 6).

\section{Discussion}

The results showed that $\mathrm{H} 1$ is significantly supported. This finding is compatible with findings of the Park et al. [35]. In these studies, CoO is an important factor for perception of consumers of luxury branded

\begin{tabular}{|l|c|c|c|c|c|}
\hline Predictor & Items & $\boldsymbol{\alpha}$ & $\boldsymbol{\beta}$ & $\mathbf{t}$-Value & $\mathbf{p}$-Value \\
\hline Country-of-Origin & 4 & 0.726 & 0.146 & 2.138 & $0.023^{\star *}$ \\
\hline
\end{tabular}

**Denotes significance at the 0.05 level.

Table 2: Regressions of $\mathrm{CoO}$ of consumer perception toward branded product (4 items, $\alpha=0.720$ ).

\begin{tabular}{|l|c|c|c|c|c|}
\hline Predictor & Items & $\boldsymbol{\alpha}$ & $\boldsymbol{\beta}$ & t-Value & $\mathbf{p}$-Value \\
\hline Country-of-Origin & 6 & 0.721 & 0.221 & 3.560 & $0.000^{* *}$ \\
\hline
\end{tabular}

**Denotes significance at the 0.05 level.

Table 3: Regressions of $\mathrm{CoO}$ of purchase intention toward branded product (6 items, $\alpha=0.720$ ).

\begin{tabular}{|l|c|c|c|c|c|}
\hline Predictor & Items & $\boldsymbol{\alpha}$ & $\boldsymbol{\beta}$ & t-Value & p-Value \\
\hline Consumer perception & 6 & 0.714 & 0.312 & 5.056 & $0.000^{* \star}$ \\
\hline
\end{tabular}

${ }^{* *}$ Denotes significance at the 0.05 level.

Table 4: Regressions of consumer perception of purchase intention toward branded product ( 6 items, $\alpha=0.720$ ).

\begin{tabular}{l|c|c|c|c|c|}
\hline Predictor & Items & $\boldsymbol{\alpha}$ & $\boldsymbol{\beta}$ & t-Value & $\mathbf{p}$-Value \\
\hline Manufacturing process & 3 & 0.723 & -0.219 & -2.453 & $0.011^{* *}$ \\
\hline
\end{tabular} **Denotes significance at the 0.05 level.

Table 5: Regressions of manufacturing process of $\mathrm{CoO}$ toward branded product (3 items, $\alpha=0.720$ ).

\begin{tabular}{|l|c|c|c|c|c|}
\hline Predictor & Items & $\boldsymbol{\alpha}$ & $\boldsymbol{\beta}$ & t-Value & p-Value \\
\hline $\begin{array}{l}\text { Product technological } \\
\text { complexity }\end{array}$ & 3 & 0.879 & -0.187 & -2.215 & $0.034^{* *}$ \\
\hline
\end{tabular}

${ }^{* *}$ Denotes significance at the 0.05 level.

Table 6: Regressions of product technological complexity of $\mathrm{CoO}$ toward branded product ( 3 items, $\alpha=0.720$ ). 
Citation: Abdolvand MA, Forough A, Targhi ST (2017) Investigation the Effect of Country-of-Origin on Consumer Perception and Purchase Intention of Luxury Brands: Case Study - Luxury Branded of Switzer Watches. J Account Mark 6: 255. doi: 10.4172/2168-9601.1000255

Page 4 of 5

goods. Results of testing the hypotheses $\mathrm{H} 2$ and $\mathrm{H} 3$ indicated that effect of $\mathrm{CoO}$ and consumer perception of luxury brand on purchase intention is significant. Our findings are consistent with the findings from the previous study from Bower and Landreth [33]. Supporting the hypotheses $\mathrm{H} 2$ and $\mathrm{H} 3$ indicated that perception of consumers towards country-of-origin significantly affected their purchase intention. Thus when a consumer has a significant perception toward $\mathrm{CoO}$ of luxury branded product, this will have effect on his/her purchase intention.

Regression analysis on hypotheses H4 and H5 showed significant influence of manufacturing process and product technological complexity on CoO. Accepting the hypotheses $\mathrm{H} 4$ and $\mathrm{H} 5$ means that the assembly, design, high and low technologies will more likely influence country-of-origin. . Our findings are consistent with the findings from the previous studies [34]

\section{Conclusion}

There has been a lot of research on the $\mathrm{CoO}$ effect and its influence in product evaluation. However, no research has been done to study the effect of $\mathrm{CoO}$ on consumer perception and purchase intention of luxury brands. In this study we examined $\mathrm{CoO}$ affecting on perception and purchase intention of consumers. We attempted to conceptualize the processes that affect the consumer perception and purchase intention variables that used for luxury branded products. A conceptual model was used to assess the effects of variables on each other using regression analysis. Results of hypotheses testing indicated that $\mathrm{CoO}$ has positive effect on consumer perception and purchase intention of luxury brands of watches. Like the other researches the limitations of this study are: There are many factors affecting on $\mathrm{CoO}$. But in this study because of time limitation we didn't examined all factors influencing on $\mathrm{CoO}$.

Questionnaire, as data gathering tools, the respondents may not answer the questions exactly according to what they think or behave. Statistical society of this study was consumers of luxury branded of Switzer watches. So development of statistical society to other luxury brand with different products decreases the limitation of study.

For future studies, we suggest that:

1. In this research only two factors have only been tested on $\mathrm{CoO}$. Researchers may examine other factors affecting on $\mathrm{CoO}$ with extensive researches.

2. By extending this study to other luxury branded products, we can reach to better results and understanding about the role of $\mathrm{CoO}$ on consumer perception and purchase intention of luxury brands.

\section{References}

1. Bloemer J, Brijs K, Kasper H (2009) The CoO-ELM model: a theoretica framework for the cognitive processes underlying country of origin-effects. European Journal of Marketing 43: 62-89.

2. Usunier JC, Cestre G (2007) Product ethnicity: Revisiting the match between products and countries. Journal of International Marketing 15: 32-72.

3. Roth MS, Romeo JB (1992) Matching product category and country image perceptions: A framework for managing country-of-origin effects. Journal of International Business Studies 23: 477-497.

4. Hooley GJ, Shipley D, Krieger N (1988) A method for modelling consumer perceptions of country of origin. International Marketing Review 5: 67-76.

5. Wang CK, Lamb CW (1983) The impact of selected environmental forces upon consumers' willingness to buy foreign products. Journal of the Academy of Marketing Science 11: 71-84

6. Wall M, Heslop LA (1986) Consumer attitudes toward Canadian-made versus imported products. Journal of the Academy of Marketing Science 14: 27-36.
7. Anholt S (2003) Brand new justice: The upside of global branding. Oxford Butterworth-Heinemann.

8. Kim HS, Shin EY, Cheng A, Lennon J, Liu WS (2015) Influence of design workmanship, and familiarity on perceptions of country-of-origin apparel brands: A study of consumers in the US, China and Japan. Journal of Global Fashion Marketing 6: 265-277.

9. Bomsel O (1995) The luxury industry or how to associate objects and representations. Realites Industrielles-Annales des Mines, pp: 14-20.

10. Dubois B, Czellar S, Laurent G (2005) Consumer segments based on attitudes toward luxury: empirical evidence from twenty countries. Marketing Letters 16 115-128.

11. Kapferer JN (1997) Managing luxury brands. Journal of Brand Management 4: 251-260.

12. Kapferer JN (1998) Why are we seduced by luxury brands? Journal of Brand Management 6: 44-49.

13. Vigneron F, Johnson LW (1999) A review and a conceptual framework of prestige seeking consumer behavior. Academy of Marketing Science Review 3.

14. Vigneron F, Johnson LW (2004) Measuring perceptions of brand luxury. The Journal of Brand Management 11: 484-506.

15. Agrawal J, Kamakura WA (1999) Country of origin: a competitive advantage. International Journal of Research in Marketing 16: 255-267.

16. Roth KP, Diamantopoulos A (2009) Advancing the country image construct. Journal of Business Research 62: 726-740.

17. Veale R, Quester P (2009) Do consumer expectations match experience? Predicting the influence of price and country of origin on perceptions of product quality. International Business Review 18: 134-144.

18. Verlegh PWJ, Steenkamp JBEM, Meulenberg MTG (2005) Country-of-origin effects in consumer processing of advertising claims. International Journal of Research in Marketing 22: 127-139.

19. Hong ST, Wyer RS Jr (1989) Effects of country-of-origin and product attribute information on product evaluation: An information processing perspective. Journal of Consumer Research 16: 175-187.

20. Janda S, Rao CP (1997) The effect of country-of-origin related stereotypes and personal beliefs on product evaluation. Psychology and Marketing 14: 689

21. Nagashima A (1970) A comparison of Japanese and US attitudes toward foreign products. The Journal of Marketing 34: 68-74.

22. Nagashima A (1977) A comparative 'made-in' product image survey among Japanese businessmen. The Journal of Marketing 41: 95-100.

23. Peterson RA, Jolibert AJP (1995) A meta-analysis of country-of-origin effects Journal of International Business Studies 26: 883-899.

24. Verlegh PWJ, Steenkamp JBEM (1999) A review and meta-analysis of countryof-origin research. Journal of Economic Psychology 20: 521-546.

25. Beverland MB (2005) Crafting brand authenticity: The case of luxury wines Journal of Management Studies 42: 1003-1029.

26. Beverland M (2006) The 'real thing': Branding authenticity in the luxury wine trade. Journal of Business Research 59: 251-258.

27. Postrel V (2003) The substance of style: How the rise of aesthetic value remaking commerce, culture and consciousness. New York: Harper-Collins Publishers.

28. Han TI, Stoel L (2016) The effect of social norms and product knowledge on purchase of organic cotton and fair-trade apparel. Journal of Global Fashion Marketing 7: 89-102.

29. Miller-Spillman KA, Lee MY, Graham MA, Cho B (2016) Consumer groups for Ghanaian fabric products, based on aesthetics and socially responsible shopping behavior. Journal of Global Fashion Marketing 7: 120-131.

30. Napoli J, Dickinson SJ, Beverland MB, Farrelly F (2014) Measuring consumerbased brand authenticity. Journal of Business Research 67: 1090-1098.

31. Newman GE, Dhar R (2014) Authenticity is contagious: Brand essence and the original source of production. Journal of Marketing Research 51: 371-386.

32. Wood VR, Darling JR (1993) The marketing challenges of the newly 
Citation: Abdolvand MA, Forough A, Targhi ST (2017) Investigation the Effect of Country-of-Origin on Consumer Perception and Purchase Intention of Luxury Brands: Case Study - Luxury Branded of Switzer Watches. J Account Mark 6: 255. doi: 10.4172/2168-9601.1000255

Page 5 of 5

independent republics: product competitiveness in global markets. Journal of International Marketing, pp: 77-102.

33. Bower AB, Landreth $S$ (2001) Is beauty best? Highly versus normally attractive models in advertising. Journal of Advertising 30: 1-2.

34. Maxham III JG, Netemeyer RG (2003) Firms reap what they sow: the effects of shared values and perceived organizational justice on customers' evaluations of complaint handling. Journal of Marketing 67: 46-62.

35. Whan Park C, MacInnis DJ, Priester J, Eisingerich AB, lacobucci D (2010) Brand attachment and brand attitude strength: Conceptual and empirical differentiation of two critical brand equity drivers. Journal of Marketing 74: 1-7. 